\title{
ECA 3O ANOS: DIREITO À EDUCAÇÃO E INFÂNCIA
}

\section{ECA 30 YEARS: RIGHT TO EDUCATION AND CHILDHOOD}

\author{
Thaís Pimenta Guimarães \\ Pontifícia Universidade Católica de Minas Gerais - PUC MINAS \\ Laís Pimenta Guimarães \\ Pontifícia Universidade Católica de Minas Gerais - PUC MINAS
}

\section{RESUMO}

O presente trabalho tem como objetivo principal promover, criticamente, uma consciência pública sobre a importância e implementação da Lei n. ${ }^{\circ}$ 8.069/90, nomeada Estatuto da Criança e Adolescente - ECA, a partir do marco de celebração de seus 30 anos de vigência. A reflexão trazida pretende evidenciá-la como o principal instrumento normativo do Brasil para a proteção da população infanto-juvenil, sobretudo com a visão contextual da sua condição peculiar de desenvolvimento e posição de sujeito de direitos, dentre tantos, à educação infantil, no que diz respeito a ordem jurídica constitucional positivada e legislação correlata. $\mathrm{E}$ tudo isso se dá no nível discursivo de cuidado e proteção da infância como uma fase da vida humana, integrada a dimensão da cidadania, consideravelmente através do dever do Estado e da família, em colaboração com a sociedade. Ao ponto que compara os principais fatos e motivos que substituíram o antigo Código de menores e o assistencialismo vigente, tendo em conta a proteção e as propostas socioeducativas, sob o ângulo de avanço do ECA, com a perspectiva dirigida para o desenvolvimento pessoal e social. Em contornos interpretativos que, a conclusão desdobra-se sobre a dinâmica relacional entre ECA, educação e cidadania no intuito de formar para a infância uma voz, verdadeiramente razoável e prudente, de reconhecimento e participação política, de modo voltado a projetar uma democracia mais justa, igualitária e inclusiva.

Palavras-chave: Estatuto da Criança e Adolescente. Educação. Infância. Inclusão. Cidadania. Democracia. 
The main objective of this paper is to promote, critically, a public awareness of the importance and implementation of the Law No. 8.069/90, named the Child and Adolescent Statute - ECA, as of the 30th anniversary celebration. The reflection brought up intends to highlight it as the main normative instrument in Brazil for the protection of the children and youth population, especially with the contextual view of their peculiar condition of development and the position of the subject of rights, among many, in early childhood education, it concerns the constitutional legal order and related legislation. And all this happens at the level of care and protection of childhood as a phase of human life, integrated with the dimension of citizenship, considerably through the duty of the State and the family, in collaboration with society. To the point that compares the main facts and reasons that replaced the old Code of minors and the current assistance, taking into account the protection and socio-educational proposals, from the angle of advancement of ECA, with the perspective directed towards personal and social development. In deep interpretive contours that, the conclusion unfolds on the relational dynamics between ECA, education and citizenship in order to form for children a voice, truly reasonable and prudent, of recognition and political participation, in order to project a more democratic fair, egalitarian and inclusive.

Keywords: Statute of the Child and Adolescent. Education. Infance. Inclusion. Citizenship. Democracy. 


\section{INTRODUÇÃO}

Nos trinta anos de vigência do Estatuto da Criança e do Adolescente - ECA, a produção científica sobre o mesmo, se insere no conjunto organizado de ideias voltadas para refletir sobre sua estruturação histórica, progressista e desafiadora frente à sociedade contemporânea. Esta iniciativa deve ser saudada em esforço da educação como direito da infância, a maior sentido de privilegiar a cidadania e inclusão social.

É no marco analítico de comunicar e efetivar esse ideal, que se eleva o Estatuto da Criança e do Adolescente como o principal sistema normativo de promoção e defesa dos direitos da população infanto-juvenil brasileira, especificamente, à ótica de interesse público social e da justiça para a infância. Tal fato privilegia evidenciar a principal base de fundamentação trazida pelo ECA, a tal propósito, o princípio da proteção integral para a criança, enquanto sujeito de direito, em condição peculiar de desenvolvimento e prioridade absoluta na agenda das políticas públicas.

\section{RECORTE DO ECA SOBRE A PERSPECTIVA DO SISTEMA DE PROTEÇÃO DOS DIREITOS HUMANOS}

Partindo do contexto acima, urge afirmar que a construção dos direitos da infância ocorreu por meio de uma demanda histórica, marcada por lutas e cuja visibilidade relaciona os princípios dos tratados internacionais da Constituição Federal de 1988 (CF/88), com o Estatuto da Criança e do Adolescente. Neste sentido, Cury recorre à Bobbio para explicar esse processo, assim:

Bobbio (1992), quando reflete sobre os direitos no mundo contemporâneo, diz que a evolução dos direitos - sobretudo dos direitos sociais, para se converterem em Direito Positivo, portanto inscritos no âmbito das Constituições ou das Leis em geral - dá-se por meio de um processo. Em primeiro lugar ocorrem experiências, pressões, num jogo mais segmentado. Disto resulta algo generalizado, ou seja, há uma generalização daquela discussão, daquela pressão. Depois criam-se novas expectativas que acabam por atingir 
vários países, várias nações. Ganham, assim, um caráter de internacionalização. No caso dos direitos das crianças, a Declaração da ONU a esse respeito é de 1959 (CURY, 1988, p. 09).

Com a Declaração Universal dos Direitos do Homem, de 10 de dezembro de 1948, necessário se fez, pela primeira vez, reconhecer uma atenção específica para que se tornasse visível a criança como objeto de cuidados e proteções especiais. Para tanto, impôs-se em registro, no inciso II do artigo 25, a determinação de que "a maternidade e a infância têm direitos a cuidados e assistência especial. Todas as crianças, nascidas dentro ou fora do matrimônio, gozarão da mesma proteção social".

Daí, então, a temática se insere de modo universal pelo sistema de proteção das Nações Unidas, precisamente em caráter vinculante de tratados internacionais para os países que os assinaram, em geral, na versão de pactos internacionais de direitos humanos, a nível tanto quanto possível de instigar a comunidade internacional para a consciência de se elaborar um instrumento próprio, em projeção de ação e garantia, para os direitos da criança. Considerada como maior símbolo de expressão, no arrastar da história dos direitos do homem, a Declaração Universal dos Direitos da Criança ${ }^{1}$, de 20 de novembro de 1959, surge sobre a justificativa de que "a Humanidade deve dar à criança o melhor de seus esforços".

Dessa inciativa, de forma consistente e organizada, estabeleceu-se no marco moral para os direitos da criança, com a missão de proteção especial; oportunidades e facilidades necessárias ao pleno desenvolvimento saudável e harmonioso; permissão de uso dos benefícios relativos à seguridade social, incluindo-se a adequada nutrição, moradia, recreação e serviços médicos; receber educação e ter proteção contra todas as formas de negligência, crueldade e exploração. Certamente que, dentre esses motivos, a inscrição de

\footnotetext{
${ }^{1}$ Coloca-se em evidência, que a Assembleia Geral das Nações Unidas proclamou a Declaração Universal da Criança para a importante função de proteção e cuidados, "com vista a uma infância feliz e ao gozo, para bem da criança e da sociedade, dos direitos e liberdades aqui estabelecidos e com vista a chamar a atenção dos pais, enquanto homens e mulheres, das organizações voluntárias, autoridades locais e Governos nacionais, para o reconhecimento dos direitos e para a necessidade de se empenharem na respectiva aplicação através de medidas legislativas ou outras progressivamente tomadas de acordo com os seguintes princípios [...]".
} 
seu Princípio 7 entra numa expressão de peso histórico para o estudo, expressamente, a sentir do conteúdo em investimento de que, "a criança tem direito de receber a educação, que será gratuita e obrigatória pelo menos nas etapas elementares."

Em que pese sua existência, a Declaração Universal dos Direitos da Criança assentou no campo da moralidade, sobretudo, sem previsão de coerção normativa ante as Nações envolvidas. Nesse rumo, a Convenção Internacional sobre os Direitos da Criança veio a ser aprovada, em 20 de novembro de 1989, na propositura de subsidiar a Declaração Universal dos Direitos da Criança. E assim sendo, estruturada em características próprias, dentre as quais, em destaque, a mais importante está no seu caráter de organizar-se como um instrumento normativo de direito internacional, o ponto principal recaiu expressamente na previsão da obrigação dos países participantes. Cabendo aqui traçar que o Brasil assinou a Convenção Internacional sobre os Direitos da Criança, em linha sucessória à Declaração Universal dos Direitos da Criança, de tal maneira a incluí-la no ordenamento jurídico nacional, mediante registro com o Decreto $n .^{0} 99.710$, de 21 de novembro de 1990. Dentro de uma lógica que, surge um novo paradigma, em torno da Convenção Internacional sobre os Direitos da Criança, com a introdução da Doutrina da Proteção Integral para todos os direitos e todas as liberdades inscritas na Declaração Universal dos Direitos Humanos.

Sem dúvidas, a partir dessa nova regência internacional, a criança passa ser amparada sobre três enfoques - proteção, promoção e defesa de seus direitos, ao maior e melhor modo, como um microssistema aberto de regras e princípios, que refletiu nos seguintes regramentos: a criança adquire o status de sujeito de direito, no que toca a tutela e efetividade dos princípios norteadores dos direitos humanos; fixa a condição peculiar de pessoa humana em desenvolvimento e, porquanto, sujeita a uma legislação especial; por fim, goza de prioridade absoluta na garantia de seus direitos fundamentais.

De fato, tal teoria origina-se do próprio preâmbulo da Declaração Universal dos Direitos da Criança, posto a previsão de ter declarado a necessidade de um sistema de proteção especial, quando fundamenta "que a criança, em razão de sua falta de maturidade física e intelectual, tem necessidade de proteção jurídica apropriada antes e 
depois do nascimento". Além disso, seu segundo princípio, também, reforça esse ideário da criança com proteção diferenciada e gozo de oportunidades e serviços, mediante lei ou outros meios, a pretexto de que seja resguardada de maneira saudável e normal, bem como em pleno exercício de liberdade e dignidade. A estas razões somadas que se concluiu, em especial, o que deve ser motivo de interesse superior da criança.

A partir dessa ideia, a Convenção Internacional sobre os Direitos da Criança servese como um sistema internacional aberto, à extensão e interpretação, com todos os outros "instrumentos internacionais" 2 , traduzidos em prioridade de direitos da infância, à luz da Doutrina da Proteção Integral.

Com isso, observa-se que a Convenção Internacional sobre os Direitos da Criança amplia o escopo normativo em esforço conjunto com os Estados-Nações, no sentido amplo, de reservar a Doutrina da Proteção integral em direção ao contexto universal dos direitos humanos, desta feita, com a educação para a infância. Dando visibilidade a esse aspecto, o direito à educação dispôs inscrito na Declaração Universal dos Direitos Humanos, de 10 de dezembro 1948, em seu Artigo 2633, em suma, prosseguindo a pressuposto de exercício dos demais direitos humanos (civis, econômicos, políticos, culturais e sociais).

\footnotetext{
2 A rigor, a Convenção sobre os Direitos da Criança preceitua, expressamente, os instrumentos internacionais que se comprometem com a proteção especial da criança, quais sejam, [...] "Declaração de Genebra de 1924 sobre os Direitos da Criança e na Declaração Universal dos Direitos da Criança adotada pela Assembleia Geral em 20 de novembro de 1959, e reconhecida na Declaração Universal dos Direitos Humanos, no Pacto Internacional de Direitos Civis e Políticos (em particular nos artigos 23 e 24), no Pacto Internacional de Direitos Econômicos, Sociais e Culturais (em particular no artigo 10) e nos estatutos e instrumentos pertinentes das Agências Especializadas e das organizações internacionais que se interessam pelo bem-estar da criança."

$3 \mathrm{O}$ artigo 26 tem por objetivo destacar a educação no centro dos direitos humanos, nos termos de que:

"§1. Toda pessoa tem direito à instrução. A instrução será gratuita, pelo menos nos graus elementares e fundamentais. A instrução elementar será obrigatória. A instrução técnico-profissional será acessível a todos, bem como a instrução superior, esta baseada no mérito. §2. A instrução será orientada no sentido do pleno desenvolvimento da personalidade humana e do fortalecimento do respeito pelos direitos humanos e pelas liberdades fundamentais. A instrução promoverá a compreensão, a tolerância e a amizade entre todas as nações e grupos raciais ou religiosos, e coadjuvará as atividades das Nações Unidas em prol da manutenção da paz. §3. Os pais têm prioridade de direito na escolha do gênero de instrução que será ministrada a seus filhos."
} 
Para a condução desse eixo, a educação para a infância é introduzida como um direito humano, que versa em padrão minimamente existencial para se ter uma vida digna. Logo, implica um marco conceitual e particular, com importantes desdobramentos nesse estudo como:

[...] a qualidade intrínseca e distintiva reconhecida em cada ser humano que o faz merecedor do mesmo respeito e consideração por parte do Estado e da comunidade, implicando, neste sentido, um complexo de direitos e deveres fundamentais que assegurem a pessoa tanto contra todo e qualquer ato de cunho degradante e desumano, como venham a lhe garantir as condições existenciais mínimas para uma vida saudável, além de propiciar e promover sua participação ativa e co-responsável nos destinos da própria existência e da vida em comunhão com os demais seres humanos, mediante o devido respeito aos demais seres que integram a rede da vida (SARLET, 2010, p. 70).

Nesse passo, a Constituição da República Federal de 1988 acompanha a importância da prática do diálogo e dos benefícios da Doutrina da Proteção Integral, a bem da inscrição em seus artigos 227 à 229, ao reconhecer a criança com dignidade própria e sujeito de direito, no mínimo, que ora se propõe, com a educação como direito fundamental.

Art. 227. É dever da família, da sociedade e do Estado assegurar à criança, ao adolescente e ao jovem, com absoluta prioridade, o direito à vida, à saúde, à alimentação, à educação, ao lazer, à profissionalização, à cultura, à dignidade, ao respeito, à liberdade e à convivência familiar e comunitária, além de colocá-los a salvo de toda forma de negligência, discriminação, exploração, violência, crueldade e opressão, além de colocálos a salvo de toda forma de negligência, discriminação, exploração, violência, crueldade e opressão.

\section{Sintetizando essas conclusões, Luciano Alves Rossato, Paulo Eduardo Lépore e Rogério Sanches Cunha (2011, p. 74) explicam que o artigo:}

Pretende, pois, que a família se responsabilize pela manutenção da integridade física e psíquica, a sociedade pela convivência coletiva harmônica, e o Estado pelo constante incentivo à criação de políticas públicas. Trata-se de uma responsabilidade que, para ser realizada, necessita de uma integração, de um conjunto devidamente articulado de políticas públicas. Essa competência difusa, que responsabiliza uma diversidade de agentes pela promoção da política de atendimento à criança e ao adolescente, tem por objetivo ampliar o próprio alcance da proteção dos direitos infanto juvenis. 
O artigo 227 da $\mathrm{CF} / 88$ propôs uma responsabilidade solidária entre a família, a sociedade e o Estado, na máxima medida possível, para assegurar os direitos especiais inerentes às crianças. Impôs-se a proteger, com absoluta prioridade, os direitos fundamentais da infância sobre esforço de compromisso mútuo, tendo em vista sua condição específica de pessoa em desenvolvimento.

Toda essa noção serve para ampliar a lição de Bobbio (2014, p. 31), basicamente, que a evolução dos direitos, dada a internacionalização, assume "uma nova linha de tendência, que se pode chamar de especificação; ela consiste na passagem gradual, porém cada vez mais acentuada, para uma ulterior determinação dos sujeitos titulares de direitos”. Com isso, segue explicando que, essa especificação ou diferenciação ocorre em relação ao gênero, às necessidades especiais e o respeito "às várias fases da vida (BOBBIO, 2014, p. 31)"4. Nesta sistematização, tratou de apontar a infância, segundo o qual, compõe a especificidade de uma fase da vida, com revelação na educação escolar, em proposição de direito à diferença.

Esta conclusão se confirma e evidencia ante o processo de evolução dos direitos, prioritariamente, a peculiaridade de direito social, no que confere recorte universal com a Educação escolar, na dimensão democrática de direito fundamental. Identifica-se, assim, por efeito do alto significado social que reveste a educação, em face de dever do Estado e direito da cidadania para todas as crianças, de maneira concreta, com o efetivo acesso e atendimento.

A relevância para tanto é elevada com a universalidade do direito da criança à educação, em uma perspectiva de habilitar sua instrumentalidade simultânea, de direito individual e coletivo, na base do papel do Estado, com o progresso de uma democracia mais participativa, inclusiva e justa. Neste contexto, o artigo $205 \mathrm{da} \mathrm{CF} / 88^{5}$ passa a reger

\footnotetext{
4Empreende um levantamento, com a Declaração dos Direitos da Criança de 1959, diante da ONU, a partir da precedência Declaração de Genebra, conectada aos auspícios da Liga das Nações, cuja tutela versada com a proteção à criança.

5Art. 205. A educação, direito de todos e dever do Estado e da família, será promovida e incentivada com a colaboração da sociedade, visando ao pleno desenvolvimento da pessoa, seu preparo para o exercício da cidadania e sua qualificação para o trabalho.
} 
o eixo da agenda política, com a educação dignificada como "direito de todos e dever do Estado e da família”, em coparticipação da sociedade, e cujos fins voltam para promover o exercício da cidadania e desenvolvimento da pessoa. Obviamente, dada aqui à recorte da diferença para uma das fases da vida com a infância.

Nessa perspectiva, está a se referir particular ânimo de um dos principais dilemas com que se tem debatido a temática, expressamente, ao situar o atual cenário de crise pandêmica e congelamento para a educação, à avaliação de ampliação do acesso, promoção de equidade, garantia de estrutura, ausência de qualidade e dentre outras razões. Inferir essa realidade, significa resistir em defesa da educação escolar mediante um direito indisponível da criança, lançando luta por justiça social, em mobilização contra retrocesso e efetiva realização de um direito fundamental.

Direcionar a educação escolar mediante um direito humano fundamental, mais do que oportuno, é essencial para aperfeiçoar sua inscrição na dimensão da cidadania em um Estado Social e Democrático de Direito. O que não justifica, nem induz, qualquer possibilidade de descomprometimento do Estado brasileiro, visto constar de um direito prescrito por ordem político-jurídica democrática, a bem de reforço da Lei de Diretrizes e Bases da Educação - LDB (Lei n. ${ }^{0}$ 9.394/96), com especial objetivo de desenvolvimento da pessoa, desta feita, criança-cidadã, ao giro forte de aptidão para influenciar os rumos futuros do país.

Com ênfase de especialidade, a LDB difundiu o direito da criança à educação como uma etapa da educação básica, de fato, prevendo estrutura e funcionamento mediante sistema de ensino. Isto significou racionalizar e organizar a educação básica para um agir especial com seus propósitos, em sentido certo de afirmar-lhe a singularidade. Esta se remete ao lúdico, ao estético pelos quais se garante um respeito a este ciclo da existência. Outro fator especial é que, a LDB reserva a educação escolar com a forma pública e gratuita, dada a nível de atuação prioritária do município, à lógica do artigo $30 \mathrm{da} C \mathrm{~F} / 88$, 
em traço articulado de regime colaborativo com a União e os Estados, nos termos do artigo $211 \mathrm{da} \mathrm{CF} / 88^{6}$.

A despeito dessa abordagem exclusiva na LDB, à vista de detalhe da Constituição Federal de 1988, não seria difícil perceber que a relevância estrutural da educação escolar, de direito da cidadania em dedução do Estado, da família e em colaboração com a sociedade, redirecionou-se a antiga noção teórica e ação social voltadas à infância. Isto conspira recordar que parte da história do Brasil sinaliza a demarcação da infância sobre duas correntes: aqueles que defendiam medidas repressivas-punitivas e outros que adotavam a educação e assistência, a maior privilégio de reconhecimento dos direitos da cidadania e direitos específicos à infância.

É justamente nesse momento que se revigora a história do sistema jurídico nacional, denominado Doutrina da Situação Irregular, com indicativo de base no Código de Menores de 1979 e na Política Nacional de Bem-Estar do Menor. O tempo faz remissão clara com o decurso do período entre império e república, expansivamente, da sociedade escravocrata para a consolidação de uma sociedade social livre e de trabalhadores, com o despertar do sentimento de nacionalidade e início do processo de industrialização, nos séculos XIX e XX.

Projetado nesse sentido, o Brasil passou por grandes transformações políticas, culturais e econômicas, o que ensejaram uma série de questões relevantes à infância e o começo do sistema de proteção social no país. Com forte inspiração no movimento iluminista europeu, a marcha da industrialização nacional desenhou a infância sobre um novo sentido social no século XIX, qual seja, de que a "criança deixa de ser objeto de

\footnotetext{
${ }^{6}$ Art. 211. A União, os Estados, o Distrito Federal e os Municípios organizarão em regime de colaboração seus sistemas de ensino.

$\S 1^{\circ}$ A União organizará o sistema federal de ensino e o dos Territórios, financiará as instituições de ensino públicas federais e exercerá, em matéria educacional, função redistributiva e supletiva, de forma a garantir equalização de oportunidades educacionais e padrão mínimo de qualidade do ensino mediante assistência técnica e financeira aos Estados, ao Distrito Federal e aos Municípios; $\S 2^{\circ}$ Os Municípios atuarão prioritariamente no ensino fundamental e na educação infantil; $\S 3^{\circ}$ Os Estados e o Distrito Federal atuarão prioritariamente no ensino fundamental e médio; $\S 4^{\circ} \mathrm{Na}$ organização de seus sistemas de ensino, a União, os Estados, o Distrito Federal e os Municípios definirão formas de colaboração, de modo a assegurar a universalização do ensino obrigatório; $\S 5^{\circ}$ A educação básica pública atenderá prioritariamente ao ensino regular.
} 
interesse, preocupação e ação no âmbito privado da família e da Igreja para tornar-se uma questão de cunho social, de competência administrativa do Estado" (RIZZINI; PILOTTI, 1995, p. 24-25). Desta reflexão, a partir da ideia de um movimento higienista, no início do século XX, a infância torna objeto de atenção e controle por parte do Estado, particularmente, mediante investida das crianças em condições de vulnerabilidade social, criticamente, categorizando-as sobre um plano moral ou criminal.

A intervenção estatal dita "social" resultou em comportamentos voltados para correção, regeneração ou reformas das crianças vulneráveis, cuja finalidade precípua era devolvê-las à sociedade como cidadãos úteis e ordeiros. Esse agir cumpriu papel essencial de evidenciar o rastro da era imperial com o recolhimento de crianças órfãs e abandonadas, submetidas às medidas assistenciais privadas e de natureza religiosa, a forma e extensão ao tempo republicano, com um novo indicativo de base para uma organização assistencial mais ampla ao atendimento da infância.

Diante desse quadro, o Estado imprimiu as bases da doutrina do direito do menor, verticalizada na interação carência/delinquência sobre a concepção da "salvação da criança" e "regeneração social", na qual veio à lume o primeiro Código de Menores, proclamado como Código Mello de Matos, em 1927. Com proposta de resgate jurídicomédico-assistencial, o Código de Menores contemplou-se em um conjunto de ações públicas e responsabilidades junto à família, a que alçava atendimento ao menor abandonado, reconhecido pelo desprezo moral ou material, em virtude de ausência ou insuficiência de amparo familiar; e ao menor delinquente, figurante no circuito da criminalidade e da exclusão social, a saber, aquele classificado como vadio, mendigo, libertino etc.

Do contexto de 1930 a 1945, o autoritarismo varguista, em que pese o curto período democrático da Constituição de 1934, marca o serviço social oferecido pelo Estado, em parceria com entes privados, a fundamental atenção às pressões sociais e políticas do movimento dos trabalhadores, com a busca de integração da família à sociedade. Dos ditames legais trabalhistas às principais implicações de serviços sociais, dentre tantas, o Departamento Nacional da Criança - DNC (Decreto-Lei n. ${ }^{0}$ 2.024/40) - e Serviço de 
Assistência do Menor - SAM (Decreto-Lei n. ${ }^{0} 3.799 / 41$ ) -destacaram em atendimento às crianças e famílias7. Com efeito, houve o aprofundamento das práticas higienistas e repressivas, contadas a excesso, abuso e violações de direitos humanos, vindo a materializarem-se, efetivamente, com o internamento compulsório e indiscriminado das crianças, desprovidas de infância e status social.

De tudo decorreram as dissenções, assentadas em transformações sociais imperadas em comando do Estado à dinâmica da relação de clientelismo e patronagem, por meio de políticas que condicionavam a concessão da cidadania à regulação ocupacional na sociedade. Não havia o reconhecimento universal das leis trabalhistas, o que determinava a noção de cidadania em sede de um sistema de estratificação social, ao largo de uma cultura política fundada nos direitos civis e políticos direcionada para todos.

Certo de que, entre 1945 e 1964, à síntese de outra experiência democrática no Brasil, a política expandiu legal e institucionalmente o sistema de proteção social, e, em assim sendo, contornou a Declaração Universal dos Direitos da Criança a um forte discurso contra o propósito do Código Menorista e atendimento do SAM.

E outro caminho não haveria de ser a reformulação da legislação, à inspiração da ampliação democrática em direção da infância para a condição de sujeito de direitos, mediante a elaboração de um novo Código de Menores, com a Lei n. ${ }^{0} 6.697$ de 1979. De fato, apresentado ao tempo da ditadura militar, implementou a Política Nacional de BemEstar do Menor - PNBEM -, que introduziu a rede nacional da Fundação do Bem-Estar do Menor - FUNABEM -, e extinguiu plenamente a SAM. Paralelamente, dispunha da mesma tendência de métodos e objetivos em relação à legislação anterior, contudo, preordenando de forma inovadora com a doutrina da situação irregular.

\footnotetext{
${ }^{7}$ À extensão da regulamentação, criou-se Conselho Nacional de Serviço Social para a execução de serviços públicos voltados para a população em condição de miséria e pobreza; Departamento Nacional da Criança, órgão vinculado ao Ministério da Educação e Saúde, em amparo da relação materno-infantil; Serviço de Assistência ao Menor, órgão diretamente subordinado ao Ministério da Justiça e Negócios do Interior, a bem da conjugação do Juizado de Menores, disciplinado pelo Decreto $\mathrm{n}^{0} \cdot 3 \cdot 799 / 41$, para menores desvalidos e delinquentes: dentre outros.
} 
Tomando-se do critério em situação irregular, o artigo $2^{\circ}$, inciso $I^{8}$, garantia sua ampliação e exequibilidade em hipóteses expressas, seguindo as diretrizes de amparo da assistência, vigilância e proteção a menores até 18 anos de idade. Ainda que tenha introduzido alguns mecanismos de controle da negligência ou abusos institucionais, a intervenção estatal continuou com a política de internamentos, bem como com a avaliação entre abandonados e delinquentes, a total atitude de discriminação para uma infância pobre.

Ao prisma histórico, cabe realçar que o Estatuto da Criança e do Adolescente, Lei n. ${ }^{\circ}$ 8.069, de 13 de julho de 1990, decolando do artigo 227 da CF/88, inova extraordinariamente os direitos da criança e do adolescente como a mais avançada legislação acerca do tipo durante a redemocratização política da sociedade brasileira. Compôs-se em um microssistema integrado dos tratados internacionais e da Constituição Federal de 1988, cujo artigo $1^{\circ}$ emprega seu objetivo expressamente no sentido de que: "esta lei dispõe sobre a proteção integral à criança e ao adolescente".

O alto grau de proteção garantido pelo Estatuto da Criança e do Adolescente pode ser avaliado pelo seu artigo $2^{\circ}$ que, ostensivamente, definiu os conceitos de criança (12 anos incompletos) e de adolescente (pessoa entre 12 e 18 anos incompletos), com distinção, para sinalizar a clara pretensão de abolir a expressão estigmatizada, "menor", da repressiva doutrina do Código de Menores de 1979.

Afinando a condição de sujeito de direitos à deveres, o ECA instituiu um sistema de intervenção distintivo para crianças e adolescentes em situação de risco e/ou vulnerabilidade social, descrito em medidas de proteção (artigo 101) ${ }^{9}$ e socioeducativas

\footnotetext{
${ }^{8}$ Art. $2^{0}$ Para os efeitos deste Código, considera-se em situação irregular o menor:

I - privado de condições essenciais à sua subsistência, saúde e instrução obrigatória, ainda que eventualmente, em razão de: a) falta, ação ou omissão dos pais ou responsável; b) manifesta impossibilidade dos pais ou responsável para provê-las; Il - vítima de maus tratos ou castigos imoderados impostos pelos pais ou responsável; III - em perigo moral, devido a: a) encontrar-se, de modo habitual, em ambiente contrário aos bons costumes; b) exploração em atividade contrária aos bons costumes; IV - privado de representação ou assistência legal, pela falta eventual dos pais ou responsável; V - Com desvio de conduta, em virtude de grave inadaptação familiar ou comunitária;

9Art. 101. Verificada qualquer das hipóteses previstas no art. 98, a autoridade competente poderá determinar, dentre outras, as seguintes medidas: I - encaminhamento aos pais ou responsável, mediante termo de responsabilidade; II - orientação, apoio e acompanhamento temporários; III - matrícula e freqüência obrigatórias em estabelecimento oficial de ensino fundamental; IV - inclusão em serviços e
} 
(artigo 112) ${ }^{10}$ à adolescentes autores de atos infracionais. Ao ressaltar essa visão sistêmica, cumpriu resguardar a condição peculiar de pessoa em desenvolvimento, ao lance de mudança paradigmática e contextual política, social e jurídica.

Dito com isso, a doutrina da situação irregular é substituída pelo paradigma da proteção integral e, consequentemente, por uma nova referência pautada pelo garantismo e reconhecimento de crianças e adolescentes como sujeitos de direitos, a que o artigo 15 do ECA destaca: "A criança e o adolescente têm direito à liberdade, ao respeito e à dignidade como pessoas humanas em processo de desenvolvimento e como sujeitos de direitos civis, humanos e sociais garantidos na Constituição e nas leis."

Por essas razões, inspirado no comando do artigo 227 da CF/88, a legislação assegura a criança e o adolescente como sujeitos de direitos fundamentais, à máxima compreensão do princípio da absoluta prioridade para a sociedade, a família e o Estado (artigo $4^{\circ}$ ). A ideia alcança prioridade com o direito à educação e suas respectivas referências de competências constitucionais, a que proclama nos artigos 53, 54 e 71 do ECA, com projeção de respeito ao acesso, oferta a e permanência na escola.

Desta iniciativa e com a responsabilidade solidária dos envolvidos, o ECA construiu um fluxo de ações que prepondera à integração social e garantia de direitos individuais e sociais, nesse sentir, por meio do cumprimento do direito à educação, com diálogo e construção para a infância. A partir dessa regulamentação, sua operacionalização inscreve-se com a concepção básica de serviços sociais e públicos, a benefícios do direito da criança à educação, à formação de valores para o exercício da cidadania e participação na vida social.

programas oficiais ou comunitários de proteção, apoio e promoção da família, da criança e do adolescente; $\mathrm{V}$ - requisição de tratamento médico, psicológico ou psiquiátrico, em regime hospitalar ou ambulatorial; VI - inclusão em programa oficial ou comunitário de auxílio, orientação e tratamento a alcoólatras e toxicômanos; VII - acolhimento institucional; VIII - inclusão em programa de acolhimento familiar; IX colocação em família substituta.

${ }^{10}$ Art. 112. Verificada a prática de ato infracional, a autoridade competente poderá aplicar ao adolescente as seguintes medidas: I - advertência; II - obrigação de reparar o dano; III - prestação de serviços à comunidade; IV - liberdade assistida; V - inserção em regime de semi-liberdade; VI - internação em estabelecimento educacional; VII - qualquer uma das previstas no art. 101, I a VI. 
Nesse encontro entre o ECA e direito da criança à educação, o discurso se sobrepõe e instaura no plano de socialização da criança, principalmente, a que vive sobre processo de exclusão, vulnerabilidade social, violência e desrespeito aos direitos fundamentais. Ater-se a esses aspectos, significa trazer à tona a instituição familiar em corresponsabilidade com a criança e o adolescente, a tal valor de fazer avançar o caráter preventivo de proteção social, em enfoque de fortalecimento dos laços e vínculos sociais, para que suas capacidades e habilidades de vida conduzam à concretização de seus direitos humanos e sociais. ${ }^{11}$

Isso tem a envolver com suas importantes mudanças de conteúdo, método e gestão, à comunicação de ações intersetoriais de atendimento socioassistenciais, a maior e melhor integração de "participação da população, por meio de organizações representativas, na formulação das políticas e no controle das ações em todos os níveis" (artigo 204, inciso I da $\mathrm{CF}$ /88). Dentre os direitos das crianças e dos adolescentes norteadas por política de atendimento infanto-juvenil, quatro linhas de ações mereceram especial atenção com o ECA:

\begin{abstract}
a. as políticas sociais básicas de caráter universal, como saúde, educação, alimentação, moradia, etc. (art. 87, item I); b. as políticas e programas de assistência social (art. 87, item II), de caráter supletivo, para aqueles de que delas necessitem; c. as políticas de proteção, que representam serviços especiais de atendimento médico e psicossocial às vítimas de negligência, maus-tratos, exploração, abuso e opressão (art. 87, item III); os serviços de identificação e localização de pais, responsáveis, crianças e adolescentes desaparecidos (art. 87, IV); d. as políticas de garantias de direitos, que representam as entidades e os aparatos jurídicos e sociais de proteção dos direitos individuais e coletivos da infância e juventude (art. 87, item V) (PEREZ; PASSONE, 2010, p. 666).
\end{abstract}

\footnotetext{
${ }_{11}$ Um dos paradoxos mais recente, nesse contexto, é o projeto de lei - PL n. ${ }^{0}$ 2.401/2019 - sobre homescholling ou ensino domiciliar, encaminhado pelo Presidente Jair Bolsonaro para aprovação no Congresso Nacional. A grosso modo, o texto tem como objetivo assegurar aos pais ou os responsáveis legais o direito de escolha à educação escolar que será ministra a seus filhos. E em que pese a matéria já ter sido declarada inconstitucional pelo Supremo Tribunal Federal no RE 88.8815/RS, não é aqui o lugar de entrar nos meandros de um tema tão complexo e divergente. Pois, o que interessa saber é apenas que, caso venha a ser aprovado, expressamente provocará a alteração do Estatuto da Criança e do Adolescente (ECA) - Lei n. ${ }^{\circ}$ 8069/90 e Lei de Diretrizes e Bases da Educação Nacional (LDB) - Lei n. ${ }^{\circ}$ 9.394/96.
} 
Acompanhando suas revoluções, a política de atendimento prescreveu para a competência dos municípios e, a partir dessa opção no artigo 88, inciso I do ECA, substituiu os poderes antes ilimitados das autoridades policiais e judiciárias, em face de abusos e excessos sobre as crianças e dos adolescentes perante o código menorista. Tal circunstância desmembra com funções fiscalizatórias e administrativas, paralelamente, com os conselhos tutelares, que uma vez previstos para todos os municípios, em estímulo e associação para a defesa dos direitos da criança e dos adolescentes (artigo 131 e seguintes do ECA) ${ }^{12}$, ainda não demandam em todos os lugares.

Essa ampliação da noção de responsabilidade, inclui a dimensão de controle social e incidência política no plano de dependência de recursos orçamentários e financeiros do Poder Público. Daqui, ressai-se claramente o maior desafio do ECA, qual seja, passar dos modelos ideais e dos princípios gerais a caminho da realidade prática. Desse ponto, a elaboração e execução de políticas, voltadas para metas e prioridades com a atenção integral da criança e do adolescente, encontram-se cada vez mais ineficazes, consequentemente, impeditivas para que o acesso aos direitos fundamentais seja garantido com equidade.

Pensar a importância das políticas públicas, em face dos tempos pandêmicos, é imperativo, mas integrá-la em sinônimo de superação de vulnerabilidade social também é indispensável. É exatamente a partir do manejo de políticas públicas compensatórias e complementares, em nível de expandir o acesso a valores de existência mínima, por exemplo, com a educação básica, que se conquistam indicadores de grande potencial para a redução das desigualdades rumo a uma democracia social mais justa e solidária.

\section{CONCLUSÃO}

\footnotetext{
${ }^{12}$ Art. 131. O Conselho Tutelar é órgão permanente e autônomo, não jurisdicional, encarregado pela sociedade de zelar pelo cumprimento dos direitos da criança e do adolescente, definidos nesta Lei. Art. 132. Em cada Município e em cada Região Administrativa do Distrito Federal haverá, no mínimo, 1 (um) Conselho Tutelar como órgão integrante da administração pública local, composto de 5 (cinco) membros, escolhidos pela população local para mandato de 4 (quatro) anos, permitida 1 (uma) recondução, mediante novo processo de escolha.
} 
A abordagem que, em breves linhas, aqui se fez refletida sobre a força simbólica e jurídico-política do Estatuto da Criança e do Adolescente - ECA, perpassou pela sua importância e inovação com a Doutrina de Proteção Integral. A passo de tornar mais claro que constitui um eficaz instrumento de cuidados à fase da infância e de proteção dos direitos da criança, especialmente, hoje, durante a crise pandêmica imposta sobre o mundo.

Nesta perspectiva, o trabalho foi apreendido mediante uma leitura sistêmica, de seus métodos, técnicas e organização, em giro prático, com o que adentra um olhar diferenciado por parte da ação do Estado, enfaticamente para a elaboração e regulamentação das políticas públicas sociais. À vista da criança como um sujeito de direitos humanos fundamentais, dentre os quais, em especial, a educação escolar medeia sua condição peculiar de desenvolvimento para contribuir com um projeto de sociedade que pretende ser justa, democrática e inclusiva, nos termos da Constituição República Federativa de 1988.

Quer-se com isso dizer que, em consonância com os ditames constitucionais, o ECA traz consigo a dinâmica relacional entre o direito universal à educação escolar e a cidadania ao ponto repercutido de que seja garantido uma vida digna para todas as crianças junto com a construção do bem comum. A tal maneira que, a contar dos tempos excepcionais, sem dúvidas somente o Poder Público detém todas as condições necessárias para estruturar a defesa e inclusão das crianças mais vulneráveis socialmente. Cabendo aqui concluir que, por meio do devido respeito ao Eca, o acesso ao direito à educação escolar deverá ser incluído em todos os aspectos para o qual uma resposta humanitária ao Covid-19 intenta passar sobre as crianças, fundamentalmente com a construção de um futuro melhor.

\section{Referências}

BOBBIO, Norberto. A era dos direitos. Tradução Carlos Nelson Coutinho; apresentação de Celso Lafer. -Nova ed. $-7^{\mathrm{a}}$ reimpressão, p. 01-97 - Rio de Janeiro: Elsevier, 2004. Disponível em: 
<https://edisciplinas.usp.br/pluginfile.php/297730/mod_resource/content/o/norberto -bobbio-a-era-dos-direitos.pdf $>$. Acesso em: 03 de jul. de 2020.

BRASIL. [Constituição (1988)]. Constituição da República Federativa do Brasil de 1988. Brasília, DF: Presidência da República. Disponível em: <http://www.planalto.gov.br/ccivil_03/constituicao/constituicaocompilado.htm>. Acesso em: 07 jul. 2020.

BRASIL. Decreto n.o 17.943-A, de 12 de outubro de 1927. Consolida as leis de assistencia e protecção a menores. Promulgação. Brasília, DF: Presidência da República. Disponível em: <http://www.planalto.gov.br/ccivil_03/decreto/19101929/D17943A.htm\#: :text=Revogado\%2opela\%2OLei\%20n\%C2\%BA\%206.697\%2C\%2 ode\%201979.\&text=4\%C2\%BA\%2OA\%2orecusa\%2ode\%2Oreceber,as\%2Odo\%2Ocrime \%20de\%20desacato >. Acesso em: 05 jul. 2020.

BRASIL. Decreto-Lei n.o 2.024, de 17 de fevereiro de 1940. Fixa as bases da organização da proteção à maternidade, à infância e à adolescência em todo o País. Brasília, DF: Presidência da República. Disponível em: <https://www2.camara.leg.br/legin/fed/declei/1940-1949/decreto-lei-2024-17fevereiro-1940-411934-publicacaooriginal-1pe.html\#: :text=Fixa\%20as\%2obases\%20da\%20organiza\%C3\%A7\%C3\%A3o,adolesc\% C3\%AAncia\%20em\%20todo\%200\%20Pa\%C3\%ADs. Acesso em: 10 jul. 2020.

BRASIL. Decreto-Lei n. ${ }^{0}$ 3.799, de o5 de novembro de 1941. Transforma o Instituto Sete de Setembro, em Serviço de Assistência a Menores e dá outras providências. Brasília, DF: Presidência da República. Disponível em: <https://www2.camara.leg.br/legin/fed/declei/1940-1949/decreto-lei-3799-5novembro-1941-413971-publicacaooriginal-1-pe.html>. Acesso em: 10 jul. 2020.

BRASIL. Decreto n. ${ }^{\circ}$ 99.710, de 21 de novembro de 1990. Promulga a Convenção sobre os Direitos da Criança. Brasília, DF: Presidência da República. Disponível em: $<$ http://www.planalto.gov.br/ccivil_03/decreto/19901994/d99710.htm\#: : :text=Considerando\%20que\%20o\%20Governo\%2obrasileiro,Art.\& text=2\%C2\%Bo\%2oEste\%2oDecreto\%20entra\%20em\%20vigor\%20na\%20data\%20de\% 20sua\%2opublica\%C3\%A7\%C3\%A30.>. Acesso em: 17 jul. 2020.

BRASIL. Decreto n. ${ }^{\circ}$ 591, de o6 de julho de 1992. Atos Internacionais. Pacto Internacional sobre Direitos Econômicos, Sociais e Culturais. Promulgação.

Promulgação. Brasília, DF: Presidência da República. Disponível em: <http://www.planalto.gov.br/ccivil_03/decreto/1990-1994/do591.htm>. Acesso em: 20 jul. 2020. 
BRASIL. Decreto n.o 592 , de 06 de julho de 1992. Atos Internacionais. Pacto Internacional sobre Direitos Civis e Políticos. Promulgação. Brasília, DF: Presidência da República. Disponível em: <http://www.planalto.gov.br/ccivil_03/decreto/19901994/do592.htm>. Acesso em: o8 jul. 2020.

BRASIL. Lei n. ${ }^{\circ}$ 4.513, de o1 de dezembro de 1964. Autoriza o Poder Executivo a criar a Fundação Nacional do Bem-Estar do Menor, a ela incorporando o patrimônio e as atribuições do Serviço de Assistência a Menores, e dá outras providências. Brasília, DF: Presidência da República. Disponível em: <http://www.planalto.gov.br/ccivil_03/leis/1950-1969/L4513.htm>. Acesso em: 05 jul. 2020.

BRASIL. Lei n. ${ }^{\circ}$ 6.697, de 10 de outubro de 1979. Institui o Código de Menores. Brasília, DF: Presidência da República. Disponível em: <http://www.planalto.gov.br/ccivil_03/leis/1970-1979/16697.htm>. Acesso em: o8 jul. 2020.

BRASIL. Lei n.o 8.069, de 13 de julho de 1990. Dispõe sobre o Estatuto da Criança e do Adolescente e dá outras providências. Brasília, DF: Presidência da República. Disponível em: <http://www.planalto.gov.br/ccivil_03/leis/18069.htm>. Acesso em: 03 jun. 2020.

BRASIL. Lei n.o 9.394, de 20 de dezembro de 1996. Estabelece as diretrizes e bases da educação nacional. Brasília, DF: Presidência da República. Disponível em: <http://www.planalto.gov.br/ccivil_03/leis/l9394.htm>. Acesso em: 15 ago. 2020.

BRASIL. Projeto de Lei n.o 2.401, de 17 de abril de 2019. Dispõe sobre o exercício do direito à educação domiciliar, altera a Lei no 8.069, de 13 de julho de 1990 - Estatuto da Criança e do Adolescente, e a Lei no 9.394, de 20 de dezembro de 1996, que estabelece as diretrizes e bases da educação nacional. Brasília, DF: Câmara dos Deputados. Disponível em:

<https://www.camara.leg.br/proposicoesWeb/fichadetramitacao?idProposicao=219861 5>. Acesso em: 22 ago. 2020.

BRASIL. Supremo Tribunal Federal. Recurso Extraordinário n. 888.815 Voto. Plenário. Relator: Min. Roberto Barroso. 12 set. 2018. Brasília: STF, 2018. Disponível em: <http://webcache.googleusercontent.com/search?q=cache:x9gA6GcW_RcJ:www.stf.jus .br/arquivo/cms/noticiaNoticiaStf/anexo/RE888815mAM.PDF +\&cd=1\&hl=ptBR\&ct=clnk\&gl=br $>$. Acesso em: 22 ago. 2020.

CURY, Carlos Roberto Jamil. A educação infantil como direito. In: Subsídios para Credenciamento e funcionamento de Instituições de Educação Infantil. Volume II. 
Brasília, Maio de 1998. Disponível em: <http://portal.mec.gov.br/seb/arquivos/pdf/volume_II.pdf >. Acesso em: 16 de jun. de 2020.

\section{DECLARAÇÃO UNIVERSAL DOS}

DIREITOS DAS CRIANÇAS - UNICEF. Adotada pela Assembléia das Nações Unidas de 20 de novembro de 1959 e ratificada pelo Brasil. Disponível em:

<http://www.dhnet.org.br/direitos/sip/onu/c_a/lex41.htm>. Acesso em: 07 ago. de 2020.

\section{DECLARAÇÃO UNIVERSAL DOS}

DIREITOS DO HOMEM. Adotada na IX Conferência Internacional Americana realizada em Bogotá no ano de 1948. Disponível em: <http://pfdc.pgr.mpf.mp.br/atuacao-econteudos-de-apoio/legislacao/direitos-humanos/declar_dir_homem.pdf $>$. Acesso em: 30 de jul de 2020.

\section{DECLARAÇÃO UNIVERSAL DOS}

DIREITOS HUMANOS. Adotada e proclamada pela Resolução $n^{0} 217$ A (III) da Assembleia Geral das Nações Unidas em 10 de dezembro de 1948. Assinada pelo Brasil na mesma data. São Paulo: Biblioteca Virtual de Direitos Humanos da USP. Disponível em: <http://www.direitoshumanos.usp.br/index.php/Declara\%C3\%A7\%C3\%A3oUniversal-dos-Direitos-Humanos/declaracao-universal-dos-direitos-humanos.html $>$. Acesso em: 30 de jul de 2020.

PERES, José Roberto Rus Perez; PASSONE, Eric. Políticas sociais de atendimento às crianças e aos adolescentes no Brasil. Cad. Pesqui. [online]. 2010, vol.40, n.140, p. 649-673. ISSN 0100-1574. Disponível em: <http://www.scielo.br/scielo.php?pid=So10015742010000200017\&script=sci_abstract\&tlng=es $>$. Acesso em: 13 de jul de 2020.

RIZZINI, Irene; PILOTTI, Francisco. A Arte de governar crianças: a história das políticas sociais, da legislação e da assistência à infância no Brasil. Rio de Janeiro: Instituto Interamericano Del Niño, 1995.

ROSSATO, Luciano Alves; LÉPORE, Paula Eduardo; CUNHA, Rogério Sanches. Estatuto da criança e do adolescente comentado. 2. ed. São Paulo: Editora Revista dos Tribunais, 2011.

SARLET, Ingo Wolfgang. Dignidade da pessoa humana e direitos fundamentais na constituição federal de 1988. 8. ed. Porto Alegre: Livraria do Advogado Editora, 2011. 


\section{Sobre as autoras:}

\section{Thaís Pimenta Guimarães}

Graduada em Direito. Mestre em Educação pela PUC Minas. Especialista em Direito Público Lato Sensu pela UGF. Advogada inscrita na OAB/ Seção de Minas Gerais. E-mail: thaisg_adv@yahoo.com.br

\section{Laís Pimenta Guimarães}

Graduada em Direito. Especialista em Direito Processual Lato Sensu pela PUC Minas. Advogada inscrita na OAB/Seção de Minas Gerais. 